\title{
Experimental study of the short-term efficiency of different breakwater configurations on beach protection
}

\author{
Carlo Lorenzoni $^{1}$ - Matteo Postacchini ${ }^{1}$ - Maurizio Brocchini ${ }^{1}$. \\ Alessandro Mancinelli ${ }^{1}$
}

Received: 7 August 2015 / Accepted: 27 March 2016 / Published online: 19 April 2016

(C) Springer International Publishing Switzerland 2016

\begin{abstract}
A campaign of experimental tests on a $2 \mathrm{D}$ movable-bed physical model, reproducing an Italian beach on the Adriatic Sea, has been performed in the wave flume of the "Laboratorio di Idraulica e Costruzioni Marittime" of the Università Politecnica delle Marche (Ancona, Italy), with the aim to assess the fundamental features of various breakwater configurations to be used in a beach-defence system typical of sandy, low-coastline beaches. Three emerged and three submerged configurations of rubble-mound detached breakwaters, for beach protection, placed at different distances from the shore, were tested, as well as a free beach configuration. The short-term hydrodynamic performances of the different configurations were assessed using as forcing some typical real-life intense sea-storm conditions. Wave transmission and beach protection efficiency under various intense wave conditions were obtained and related to some dimensionless parameters, amongst which a recently introduced one, $\chi$, that combines both wave and breakwater properties. Transmission coefficients were found to be about 0.4 for emerged breakwaters and in the range $0.5-0.8$ for submerged breakwaters. A net damping coefficient, defined as the wave height decay solely due to the effect of the breakwater, was measured as 0.2 for submerged breakwaters and 0.4 for the emerged ones. Further, submerged breakwaters induce an inshore mean water superelevation that increases with $\chi$,
\end{abstract}

Carlo Lorenzoni

c.lorenzoni@univpm.it

Matteo Postacchini

m.postacchini@univpm.it

Maurizio Brocchini

m.brocchini@univpm.it

Alessandro Mancinelli

a.mancinelli@univpm.it

1 DICEA, Università Politecnica delle Marche, Ancona, Italy whilst it decreases in the case of emerged breakwaters. Wave transmission is well represented by existing literature relations for both emerged and submerged breakwaters. Emerged breakwaters are more protective than submerged ones, but, at the same time, are more sensitive to changes in structure dimensions or positions. This is confirmed by the analysis of the momentum flux within the nearshore region, which is much larger for the submerged breakwaters. Such structures induce large swash-zone motions and sediment transport, comparable to those occurring at an unprotected beach.

Keywords Coastal defence $\cdot$ Rubble-mound breakwaters · Maritime physical models $\cdot$ Movable-bed models

\section{Coastal defence structures for low-coastline Adriatic beaches}

The Italian side of the Adriatic coast is extensively protected, from beach erosion, by several defence structures. Sandy or gravel beaches ("low-coastline beaches") are typical of such coast, exception made for the littorals of Gargano, Conero and other smaller promontories. Hence, coastal erosion is a major problem, which is often mitigated by means of coastal defence structures that dissipate the energy of the approaching waves, especially by inducing wave breaking. In particular, the $170 \mathrm{~km}$ of the Marche Region coast is protected by more than $100 \mathrm{~km}$ of defence structures, less than $30 \%$ of low-coastline beaches are still free of rigid defence structures and this length is progressively reducing.

Since the beginning of the last century, the first extensively used defence structures were emerged rubble-mound breakwaters, built in barrier sequences to mitigate erosion. As a drawback emerged breakwaters induced a number of undesired phenomena, such as tombolo and salient for- 
mation, mud and seaweed deposits, degradation of water quality, downdrift beach erosion, pronounced local seaward scour and visual impact. With the aim to solve some of these problems, rubble-mound submerged breakwaters have been used since the 1980s, in view of their reduced visual/environmental impact. However, if compared to the emerged breakwaters, submerged barriers are thought to be less efficient for coastal protection purposes and may, at times, be the cause of hazards (see, for example, the generation of dangerous rip currents through the narrow gaps between contiguous barriers, as described in Soldini et al. 2009). Other limits of the working of submerged structures are the downdrift erosion and the deep scouring at the gap areas. In summary, downdrift erosion, local scouring and rip currents are the major limits of traditional rubble-mound breakwaters, both emerged and submerged, used to defend sandy beaches along the Italian Adriatic coast.

In view of the above, alternative solutions, that reduce both environmental impacts and construction/maintenance costs, are needed. In recent years, many studies have been carried out on innovative structures that can mitigate the sea-storm impact on the beach, to guarantee, for instance, an efficacious nearshore circulation that does not deplete large amounts of sediments, using submerged, either vertical or inclined, blades (Nobuoka et al. 1996; Lorenzoni et al. 2010; Postacchini et al. 2011). Nowadays, many new solutions and examples of defence structures are available: e.g. composite systems made of breakwaters and groins to form protected cells hosting nourishments, mound-shaped artificial reefs, made of pierced concrete balls, or geotubes, used as either detached structures or breakwater cores (Pilarczyk 2000; Aminti et al. 2010; Buccino et al. 2013). Although such new solutions seem to positively influence the nearshore circulation, traditional detached breakwaters, sometimes coupled with nourishments (e.g. perched beaches, as studied by Gonzales et al. 1999), are still largely employed to protect low-coastline beaches. Hence, such structures have been extensively studied in the last decades, with the aim to better understand the role of the main parameters, like the distance from the coastline, the freeboard, and the gap dimension (e.g., see Brocchini et al. 2004; Burcharth et al. 2007). However, accurate studies on the behaviour of such structures are needed to improve their design applications, also taking into account the beach evolution during intense storms, as already analysed numerically by Postacchini et al. (2016), which can occur even in summer and lead to structural damages of touristic facilities that, too frequently, are placed very close to the shoreline.

The hydro-morphodynamics that evolves around traditional rubble-mound breakwaters is quite complex and has interactions with the swash-zone dynamics. In particular, erosion of the submerged beach can be induced by the wave-forced circulation, whilst the morphodynamics of the emerged part of the beach mainly depends on the swash motions and, for beaches with coarser sediments, also on their permeability (e.g., see Steenhauer et al. 2012; Kikkert et al. 2013). The high-energy generated swash motions force rapid morphological changes associated with the generation of an emerged berm.

During sea storms, low-crested breakwaters induce superelevations of the mean water level within the protected zone, i.e. water "piling-up" (or wave set-up). At emerged structures, the piling-up is due to the shoreward flowing water passing over and filtering through the structure. Such a process forces the water to filter seaward through the structure and, mostly, to flow out to sea through the narrow gaps between two contiguous barriers, this promoting intense rip currents. In the case of submerged breakwaters, the mechanism is almost the same, with a further seaward flow over the breakwater (Lorenzoni et al. 2012).

Several studies (Burcharth et al. 2007) tried to describe the entire flow pattern for both submerged and emerged lowcrested structures. Further, many experimental tests have been carried out in wave flumes to estimate the water pilingup (see, for example, Ruol et al. 2003), whilst analytical evaluations can be achieved by means of the momentum equation for the hydrodynamic equilibrium around a submerged breakwater (Calabrese et al. 2008). The water pilingup is seen to be constituted by two contributions, obtained by enforcing mass and momentum balance, and depending on: position of the breaking point, breaking depth, breakwater freeboard, incident significant wave height, transmission coefficient, breakwater geometry, flow rate and friction factor.

Many studies were dedicated to characterize the efficiency of emerged/submerged breakwaters (e.g. Pilarczyk 2003; Burcharth et al. 2007). In particular, some of them focus on hydrodynamics, sediment transport and water quality (e.g., see Lorenzoni et al. 2005). Some mainly deal with wave characteristics, i.e. transmission and reflection (e.g., Van der Meer et al. 2005), and water levels, i.e. run-up, set-up, overtopping (e.g., Losada 2008). Some analyse the shoreline long-term response in the presence of detached barriers (e.g. Larson et al. 1997).

The present work focuses on the analysis of the role played by sea-storm features on the short-term response of a protected beach. An analysis, based on dedicated laboratory experiments, of the cross-shore response of traditional rubble-mound breakwaters is here performed. The main aim is to characterize the short-term hydrodynamic efficacy of the defence configuration under various wave conditions, analysing the main strengths and weaknesses of the emerged/submerged structures and the best breakwater geometry (in particular, features like submergence, berm width, lateral slopes and distance from the shoreline), to produce the best hydrodynamic performance. A similar 
Fig. 1 Physical model of movable-bed and breakwater in the flume (left panel) and with water inside (right panel)
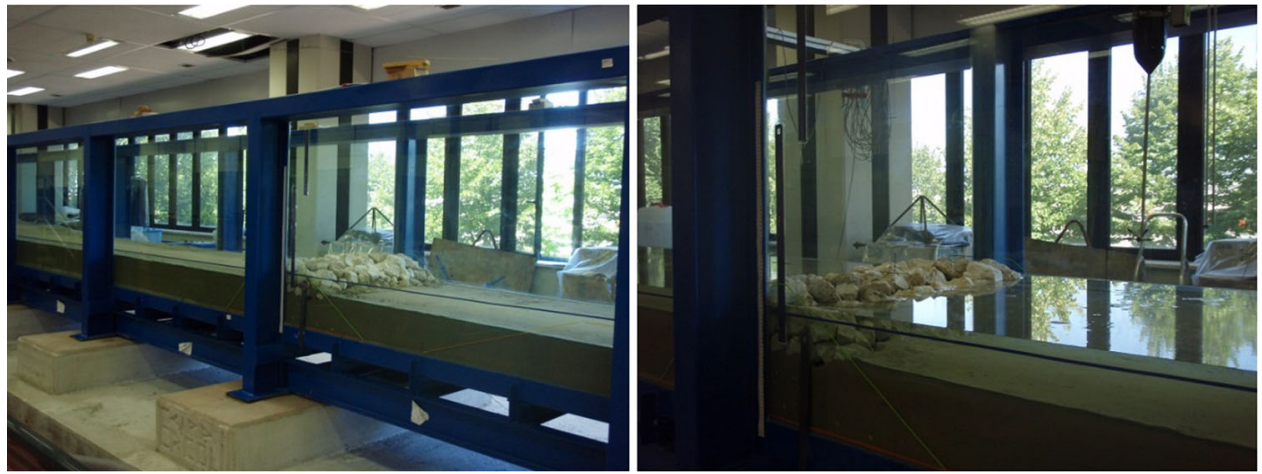

scope was that of Postacchini et al. (2016), who numerically analysed the influence of the breakwater geometry on the hydro-morphodynamics induced by different breakwater configurations subject to different sea-states. We here prefer to focus on the study of the hydrodynamics induced by different breakwater configurations. Discussion of the morphological results, partially described in Lorenzoni et al. (2012), will be further investigated in a future work.

The next section illustrates the experimental campaign, whilst results are provided in Sect. 3. Discussion and Conclusions, of Sect. 4, closes the paper.

\section{The experimental tests}

The reference case for the present analysis is the coastal defence system of the sandy beach of Gabicce Mare (along the Italian Adriatic coast, see Lorenzoni et al. 2012), which is here taken as representative of the systems used to protect low-coastline beaches.

The experimental tests were performed in the wave flume of the Laboratorio di Idraulica of the DICEA of the Università Politecnica delle Marche (Ancona, Italy, see Lorenzoni et al. 2012). The inside dimensions of the flume are: length $50 \mathrm{~m}$, width $1 \mathrm{~m}$, height from the bottom $1.3 \mathrm{~m}$. The lateral walls of the flume, in which steel vertical beams and wide glass windows alternate along both sides of the central $36 \mathrm{~m}$, enable to observe, photograph or video-record the hydrodynamics and morphodynamics of interest from the lateral sides. The wave generation system, provided by Wallingford (UK), is made of a vertical paddle with a piston-type motion. This is characterized by an absorption system, which, however, was not used for the tests at hand.

The physical model reproduces, at reduced scale, a representative cross-shore section of the protected sandy beach of Gabicce Mare. The simulated rubble-mound breakwater was realized in different positions and structure dimensions when a change of defence configuration occurred. Each breakwater was built using only one layer of stones, with an $8.5 \mathrm{~cm}$ median diameter at model scale. No damages occurred during the experimental tests (only some weak settlement), though the stones were not linked one another.

The chosen profile was first partially rectified (for simplicity sake), then reproduced in the flume as a 2D (in the vertical plane) movable-bed model with a geometrical reduced scale of 1:20 (see Fig. 1). Froude similarity was used for the hydrodynamics. The choice of the sediment size, for the surf zone, has been based on the Dean criterion, to properly down-scale the suspended sediment transport mainly occurring and dominant in the surf zone. Hence, the Dean number $N_{0}=H_{s} /\left(w_{s} T_{p}\right)$ has been conserved, with $H_{s}$ being the significant wave height, $T_{p}$ the peak period and $w_{s}$ the grain fall velocity. As a consequence, the velocity scale derived from the Froude similarity, i.e. $\sqrt{1: 20}$, is used to scale $w_{s}$. Finally, the sand of the movable-bed model ( $D_{50}$ of about $0.15 \mathrm{~mm}$ ) was chosen as suitable to simulate the natural sand of the prototype beach $\left(\mathrm{D}_{50}\right.$ of about 0.2 $\mathrm{mm})$.

Within the swash zone, where dominant is the bedload transport, the geometrically scaled criterion applied to the sediment representation seems to be more suitable than the Dean criterion, to simulate the sediment scale representation. Therefore, using the 1:20 geometrical scale and the sediment size $\mathrm{D}_{50} \sim 0.15 \mathrm{~mm}$, the resulting simulated beach evolution, is comparable to that of a prototype sediment characterized by $D_{50 \text {,prot }} \sim 3 \mathrm{~mm}$, i.e. that of a gravel beach. This explains some behaviours and effects typical of gravel beach evolutions, like the generation of large shore berms. However, for physical model needs, this is an acceptable and common trade-off between the correct representation of the suspended sediment motion, dominating in the surf zone (main focus of our study), and a (less) proper reproduction of the nearbed sediment transport, e.g. dominating within the swash zone (Hughes 1993). Further information on the morphological results can be found in the following sections and in Lorenzoni et al. (2012).

Three emerged (A, D, E) and three submerged (B, C, F) breakwater configurations, differing in cross-section geom- 
etry and/or position, were reproduced and tested. Their dimensions were chosen to reproduce, at geometrical reduced scale, those used in coastal defence systems of low-coastline Adriatic beaches. Also, a configuration with no structures (G), simulating a planar free beach, was modelled, as a benchmark case for the other configurations. The sections of the different configurations are illustrated, with different colours, in Fig. 2 and their main dimensions are shown in Fig. 3 and summarized in Table 1.

The wave attacks reproduced in the wave flume were three extreme events (labelled as OS1, OS2 and OS3), that simulated three intense sea storms actually observed in the Adriatic Sea, during 1999, 2002 and 2004 (ISPRA 2012). The storm OS2 includes the longest waves, OS3 the shortest ones. In the nearshore, refracted waves were normal enough to the beach to be well reproduced in the flume. The significant wave heights of their chronological peaks were of about $5 \mathrm{~m}$ in prototype, representing very severe conditions. Every storm was reproduced maintaining a constant mean water level to simulate the time-averaged value of the related storm-surge superelevation $(2,3.5$ and $2 \mathrm{~cm}$, in the model, respectively). The entire duration of each storm was divided into four different phases that were reproduced in a sequence of constant JONSWAP wave spectra, to simulate the complete storm. The reproduced waves are characterized by values of $H_{s}$ and $T_{p}$ that derive from: (i) a first time-series subdivision in four consecutive phases, evaluating the average value for each phase, (ii) a subsequent transfer from deep waters to the water depth of $7.48 \mathrm{~m}$ (see also Lorenzoni et al. 2012), which is the corresponding prototype depth of the
Fig. 2 Sketch of the section detail of the flume in correspondence of the positions of all the tested breakwater configurations

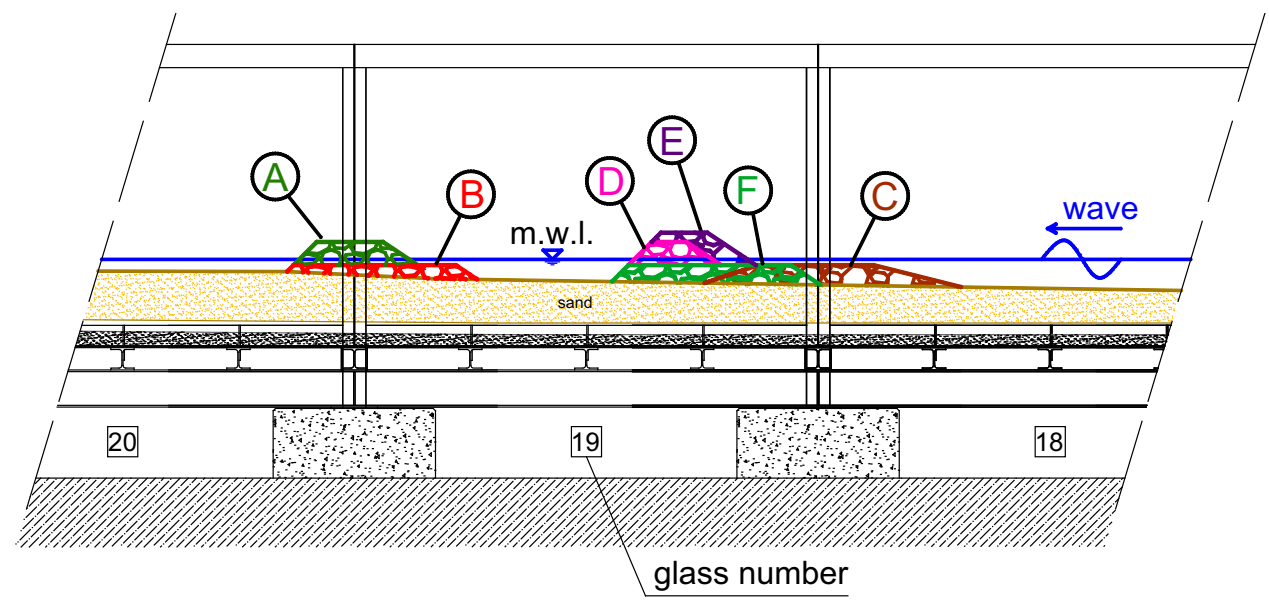

Fig. 3 Sketch of the main breakwater dimensions

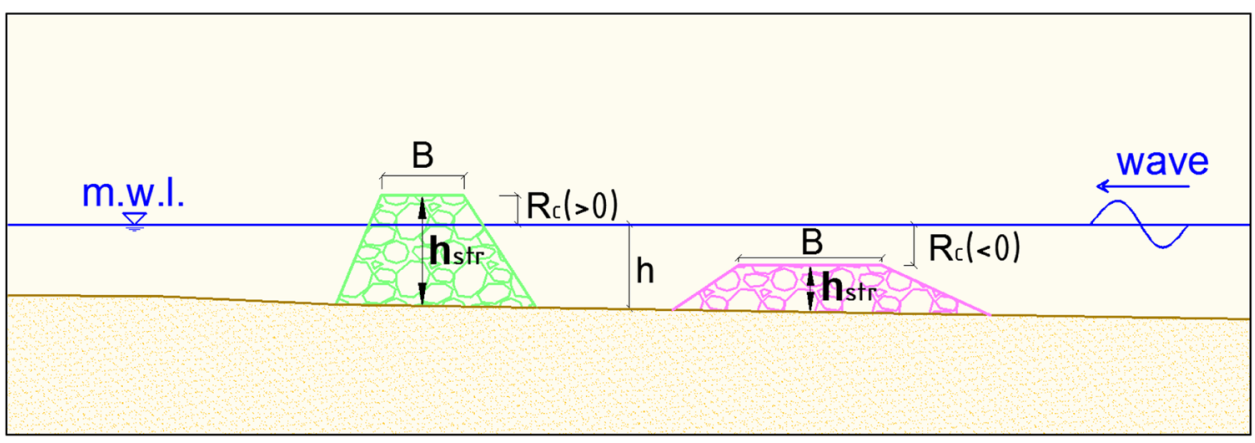

Table 1 Main dimensions and positions for the models of the different breakwater configurations

\begin{tabular}{|c|c|c|c|c|c|c|}
\hline Configuration & $\begin{array}{l}\text { Berm quote } \\
(\mathrm{mm})\end{array}$ & $\begin{array}{l}\text { Mean depth } \\
(\mathrm{mm})\end{array}$ & $\begin{array}{l}\text { Berm width } \\
(\mathrm{mm})\end{array}$ & $\begin{array}{l}\text { Offshore } \\
\text { slope }\end{array}$ & Inshore slope & $\begin{array}{l}\text { Minimum distance from } \\
\text { shoreline }(\mathrm{mm})\end{array}$ \\
\hline $\mathrm{A}$ & +75 & 60 & 286 & $2: 3$ & $1: 1$ & 480 \\
\hline B & -25 & 65 & 700 & $2: 3$ & $1: 1$ & 480 \\
\hline $\mathrm{C}$ & -25 & 110 & 500 & $1: 4$ & $1: 3$ & 660 \\
\hline $\mathrm{D}$ & +75 & 95 & 150 & $2: 3$ & $1: 1$ & 620 \\
\hline $\mathrm{E}$ & +115 & 95 & 200 & $2: 3$ & $1: 1$ & 620 \\
\hline $\mathrm{F}$ & -25 & 100 & 700 & $2: 3$ & $1: 1$ & 620 \\
\hline
\end{tabular}


Table 2 Characteristics of the reproduced sea storms at model scale

\begin{tabular}{llllllll}
\hline Wave & Phase & Duration $(\mathrm{hh}: \mathrm{mm})$ & $H_{s}(\mathrm{~m})$ & $T_{p}(\mathrm{~s})$ & $\Delta \mathrm{h}(\mathrm{m})$ & $H_{s} / L_{p 0}$ & $N_{0}$ \\
\hline OS1 & 1 & $03: 18$ & 0.090 & 1.92 & 0.02 & 0.0156 & 4.596 \\
OS1 & 2 & $01: 14$ & 0.131 & 1.76 & 0.02 & 0.0271 & 7.297 \\
OS1 & 3 & $05: 39$ & 0.102 & 1.61 & 0.02 & 0.0252 & 6.211 \\
OS1 & 4 & $08: 03$ & 0.067 & 1.42 & 0.02 & 0.0213 & 4.626 \\
OS2 & 1 & $04: 05$ & 0.046 & 1.60 & 0.036 & 0.0115 & 2.819 \\
OS2 & 2 & $04: 48$ & 0.058 & 1.90 & 0.036 & 0.0103 & 2.993 \\
OS2 & 3 & $03: 18$ & 0.111 & 2.10 & 0.036 & 0.0161 & 5.182 \\
OS2 & 4 & $13: 52$ & 0.047 & 1.85 & 0.036 & 0.0088 & 2.491 \\
OS3 & 1 & $00: 27$ & 0.083 & 1.20 & 0.02 & 0.0369 & 6.781 \\
OS3 & 2 & $00: 54$ & 0.135 & 1.92 & 0.02 & 0.0235 & 6.893 \\
OS3 & 3 & $04: 15$ & 0.083 & 1.62 & 0.02 & 0.0203 & 5.023 \\
OS3 & 4 & $10: 51$ & 0.063 & 1.36 & 0.02 & 0.0218 & 4.542 \\
\hline
\end{tabular}

wave generation paddle. More details about the transferred sea-storm phases are given in Table 2.

Water-level measurements were performed by means of 8 electro-sensitive gauges, placed and fixed at different positions along the model profile from the wave generator to the inshore zone. Instantaneous local velocities have also been measured using a pair of Acoustic Doppler Velocimeters (Vectrino, Nortek). The morphological evolution of the movable-bed profile was surveyed, at each phase of the storms, observing across the glassed side walls the beach profile, with reference to a graph paper grid. The mean value of the measures taken at both sides has been taken as the representative local seabed elevation.

We correlate the wave forcing with hydrodynamic features. Further, investigation is focused on: (1) the response to wave attacks when emerged/submerged breakwaters are used; (2) how geometry and distance to shore of the breakwaters influence the hydrodynamic performance of the different defence structures. The experimental data were evaluated and compared, enabling us to pinpoint which are the crucial parameters (e.g. cross-shore position and/or optimal berm width and quote) that must be taken into account for a proper breakwater section design.

\section{Results}

\subsection{Transmission coefficient}

The main parameters of interest here are the breakwater dimensions, the breakwater-to-shoreline distance, the transmission coefficient $K_{t}$, the wave characteristics and the water levels and their respective evolutions. Hence, these parameters and their relationships are analysed and discussed.

Focus is on wave transmission at breakwaters, wave damping and piling-up through each configuration, to get an overall assessment of the hydrodynamics; hence, the cross-shore
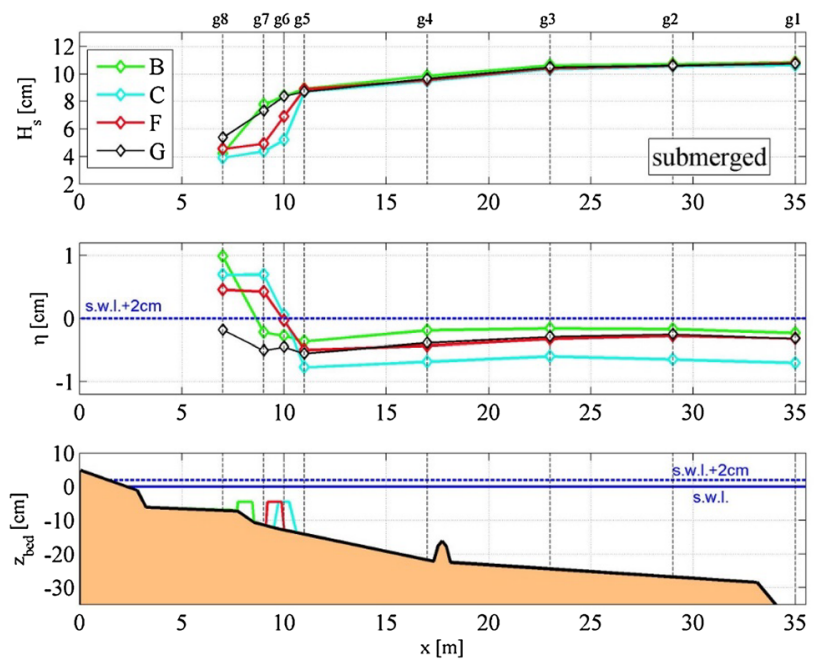

Fig. 4 Cross-shore distribution of wave height $H_{S}$ (top panel) and water surface $\eta$ (middle panel) over submerged configurations (bottom panel) during wave OS1.2. Original still water level (horizontal solid lines), still water level plus superelevation (horizontal dashed lines) and gauge locations (vertical solid lines) are also shown

profiles of the water levels collected along the model are first analysed and discussed in detail.

For purely illustrative purposes, Figs. 4 and 5 (top panels) display the wave height cross-shore distribution, measured during the storm phase OS1.2, respectively for emerged and submerged breakwater configurations. The mean water-level (middle panels) and initial beach profile (bottom panels) of each configuration is also illustrated. The same cross-shore distributions are shown for the structure-free configuration (G). Each line/colour refers to a single configuration.

An abrupt wave height decay occurs over the breakwaters of both types. The different breakwater configurations, either submerged or emerged, though placed at different distances from the shore, seem to provide similar global dissipations. The wave reduction, as expected, is larger for emerged than for submerged structures. Such reduction also occurs over 

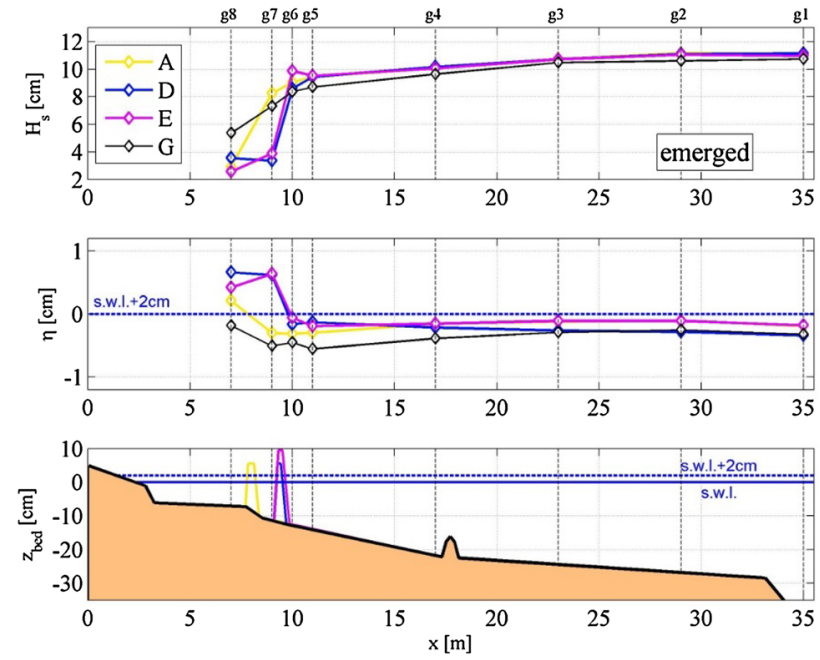

Fig. 5 Cross-shore distribution of wave height $H_{s}$ (top panel) and water surface $\eta$ (middle panel) over emerged configurations (bottom panel) during wave OS1.2. Original still water level (horizontal solid lines), still water level plus superelevation (horizontal dashed lines) and gauge locations (vertical solid lines) are also shown

the entire beach, due to the seabed evolution, some of the waves breaking before reaching the structure. Tables 3 and 4 show, respectively, the transmission coefficients estimated, for all the configurations and storm phases, as

$K_{t}^{*}=\frac{H_{s, t}}{H_{s, i}}$
$K_{t}=\frac{H_{s, t}}{H_{s, i, \text { free }}}$

where $H_{s, i}$ and $H_{s, t}$ are, respectively, the significant wave heights measured just seaward and shoreward of the breakwaters (respectively corresponding to the incident and transmitted values recorded in the presence of the breakwaters), whilst $H_{s, i \text {,free }}$ is the incident wave height measured for the unprotected beach configuration $\mathrm{G}$, with the aim to remove the influence of the wave reflection of the breakwaters. Equation (1a), i.e. $K_{t}^{*}$, gives a transmission coefficient that accounts for all processes involved in the transmission throughout the breakwater, whilst Eq. (1b), i.e. $K_{t}$, gives the classical definition of the transmission coefficient, which aims at removing the role of wave reflection (e.g., see Buccino and Calabrese 2007). We believe that the latter is a better coefficient for the analysis of the breakwater efficiency, since it takes into account the seabed evolution, providing important feedbacks in the wave transformation seaward of the barrier.

Depending on the breakwater position, the used gauge pairs were (g7-g8) for configurations A and B, (g5-g7) for $\mathrm{C}$ and $\mathrm{F}$, whilst we used (g6-g7) for D and (g5-g7) for E. To investigate the efficiency of the tested breakwaters, Tables 3 and 4 illustrate the mean transmission coefficients for each configuration. Emerged breakwaters induce mean transmis-

Table 3 Transmission coefficient $K_{t}^{*}$ for all breakwater configurations and all wave attacks

\begin{tabular}{lccccccccccccccc}
\hline Configuration & OS1.1 & OS1.2 & OS1.3 & OS1.4 & OS2.1 & OS2.2 & OS2.3 & OS2.4 & OS3.1 & OS3.2 & $\begin{array}{c}\text { OS3.3 } \\
\text { OS3.4 }\end{array}$ & $\begin{array}{c}\text { Averaged } \\
\text { value }\end{array}$ \\
\hline A & & & & & & & & & & & & & & & \\
B & 0.355 & 0.353 & 0.332 & 0.302 & 0.366 & 0.461 & 0.428 & 0.439 & 0.266 & 0.309 & 0.321 & 0.311 & 0.354 \\
C & 0.551 & 0.544 & 0.558 & 0.541 & 0.780 & 0.698 & 0.543 & 0.826 & 0.454 & 0.510 & 0.523 & 0.581 & 0.592 \\
D & 0.552 & 0.503 & 0.526 & 0.570 & 0.748 & 0.753 & 0.638 & 0.865 & 0.446 & 0.699 & 0.540 & 0.600 & 0.620 \\
E & 0.359 & 0.390 & 0.411 & 0.480 & 0.674 & 0.594 & 0.536 & 0.670 & 0.435 & 0.459 & 0.497 & 0.587 & 0.508 \\
F & 0.411 & 0.408 & 0.456 & 0.554 & 0.412 & 0.319 & 0.319 & 0.414 & 0.289 & 0.311 & 0.344 & 0.429 & 0.389 \\
Averaged value & 0.469 & 0.459 & 0.472 & 0.525 & 0.635 & 0.604 & 0.523 & 0.686 & 0.408 & 0.470 & 0.462 & 0.525 \\
\hline
\end{tabular}

Table 4 Transmission coefficient $K_{t}$ for all breakwater configurations and all wave attacks

\begin{tabular}{lccccccccccccccc}
\hline Configuration & OS1.1 & OS1.2 & OS1.3 & OS1.4 & OS2.1 & OS2.2 & OS2.3 & OS2.4 & OS3.1 & OS3.2 & $\begin{array}{c}\text { OS3.3 } \\
\text { OS3.4 }\end{array}$ & $\begin{array}{c}\text { Averaged } \\
\text { value }\end{array}$ \\
\hline A & 0.377 & 0.398 & 0.359 & 0.334 & 0.413 & 0.438 & 0.447 & 0.464 & 0.274 & 0.335 & 0.359 & 0.374 & 0.381 \\
B & 0.543 & 0.577 & 0.545 & 0.511 & 0.769 & 0.698 & 0.569 & 0.789 & 0.448 & 0.500 & 0.493 & 0.582 & 0.585 \\
C & 0.540 & 0.503 & 0.523 & 0.575 & 0.703 & 0.698 & 0.615 & 0.787 & 0.463 & 0.639 & 0.541 & 0.593 & 0.598 \\
D & 0.363 & 0.401 & 0.397 & 0.397 & 0.538 & 0.540 & 0.542 & 0.564 & 0.410 & 0.455 & 0.457 & 0.486 & 0.462 \\
E & 0.460 & 0.447 & 0.483 & 0.527 & 0.409 & 0.390 & 0.358 & 0.477 & 0.322 & 0.346 & 0.376 & 0.435 & 0.419 \\
F & 0.612 & 0.567 & 0.537 & 0.687 & 0.834 & 0.836 & 0.682 & 0.975 & 0.536 & 0.534 & 0.556 & 0.624 & 0.665 \\
Averaged value & 0.483 & 0.482 & 0.474 & 0.505 & 0.611 & 0.600 & 0.536 & 0.676 & 0.409 & 0.468 & 0.464 & 0.516 \\
\hline
\end{tabular}


sions smaller than 0.51 , whilst submerged structures induce values larger than 0.58 .

A comparison of the influence of the different wave attacks reveals that longer and more superelevated waves (OS2), which also increase wave overtopping/transmission, are easily transmitted $\left(K_{t}^{*}=0.289-0.902\right)$, whilst shorter waves (OS3) are transmitted less easily $\left(K_{t}^{*}=0.266-\right.$ 0.699). Hence, the smaller is the surge and the shorter the wavelengths, the larger is the structure efficiency. From a morphodynamic point of view, the larger impact of longer waves is also confirmed by Postacchini et al. (2016), who numerically observed that sea states characterized by larger periods induce a larger sediment motion and wider erosion/deposition patterns around submerged breakwaters. In general, though submerged barriers lead to shoreline retreats larger than emerged ones placed at the same distance to shore (as described in Sect. 3.5), the former induces smaller local scours around the structure itself (see also Lorenzoni et al. 2012).

Using the approach of Postacchini et al. (2016) for the analysis of the hydro-morphodynamics occurring around submerged structures, a dimensionless parameter accounting for the breakwater geometry and wave features is here introduced. Such a parameter accounts for the wave steepness $\left(H_{s} / L_{p}\right)$, the ratio between structure width $(B)$ and wave length $\left(L_{p}\right)$ and the ratio between the structure height $\left(h_{\text {str }}\right)$ and the water level $\left(h_{i}\right)$. Hence, we define the new parameter as

$\chi=\left(\frac{H_{s, i}}{L_{p}}\right)^{3}\left(\frac{B}{L_{p}}\right)^{0.5}\left(\frac{h_{\mathrm{str}}}{h_{i}}\right)^{1.5}$

The dependence of $K_{t}^{*}$ (left panel) and $K_{t}$ (right panel) on $\chi$ is illustrated in Fig. 6. The global best-fits of $K_{t}^{*}$ give

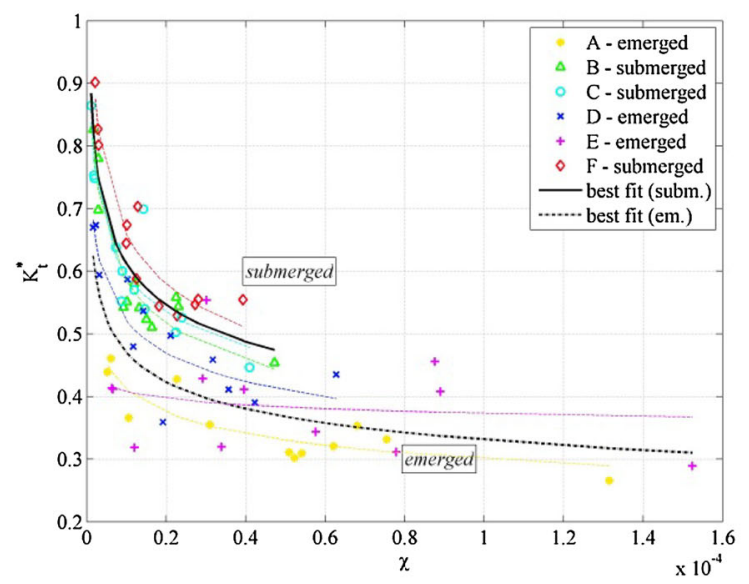

Fig. 6 Dependence of all $K_{t}^{*}(l e f t)$ and $K_{t}(r i g h t)$ on $\chi$ of all analysed wave conditions: data of submerged (B triangle, $\mathrm{C}$ open circle, $\mathrm{F}$ diamond) and emerged (A eight-pointed black star, D multi symbol, E plus
$R^{2}=0.81$ and 0.54 for, respectively, submerged (black solid line) and emerged (black dash-dotted line) configurations, whilst poorer fits are found for $K_{t}$ (respectively $R^{2}=0.77$ and 0.36 ). Use of $K_{t}^{*}$ also leads to good determination coefficients for each single submerged structure (0.85-0.92), and except for the largest structure (E), for the emerged breakwater configurations $\mathrm{A}\left(R^{2}=0.76\right)$ and $\mathrm{D}\left(R^{2}=0.79\right)$. This underlines the importance of accounting for the breakwater geometry, fundamental for wave transmission and decay. Further, Fig. 6 suggests that the wave transmission decreases with increasing wave steepness $\left(H_{s} / L_{p}\right)$, relative berm width $\left(B / L_{p}\right)$ and relative structure height $\left(h_{\mathrm{str}} / h_{i}\right)$.

Figure 6 also shows that, on average, about $40 \%$ of the incident wave is transmitted shoreward in case of emerged breakwaters, whilst it is about $50-80 \%$ for the submerged configurations. Thus, on average, the submerged structures allow a wave transmission about 40-70 \% larger than the emerged ones. The breakwaters that are closer to shore (A amongst the emerged and B amongst the submerged) are characterized by transmission coefficients smaller than those induced by the offshore-placed breakwaters (e.g., D amongst the emerged and $\mathrm{F}$ amongst the submerged). Further, comparing larger (E and C) with smaller (D and F) offshore-placed breakwaters, data and best-fit curves suggest a larger transmission induced by the latter ones. Hence, the structure dimension certainly affects the wave transmission, but the breakwater onshore/offshore location is much more important, due to the strong influence of the seabed and beach configuration.

\subsection{Net wave damping}

The wave reduction efficiency of the different breakwater configurations is also investigated by means of another analysis, which highlights the net reduction due to the breakwaters only. For example, the global seaward-to-shoreward wave

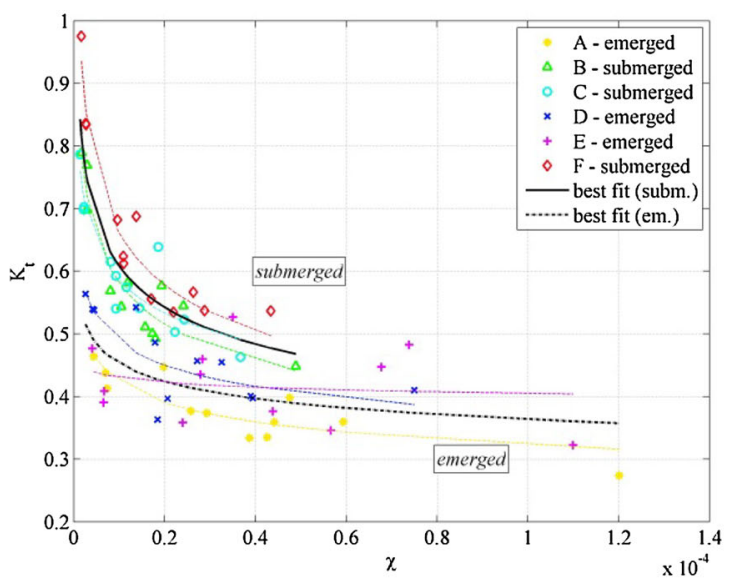

symbol) structures are fitted both individually (dashed coloured lines) and globally (black lines) using power laws 
Table 5 "Net wave damping" for all breakwater configurations and all the wave phase attacks

\begin{tabular}{lccccccccccccccc}
\hline Configuration & OS1.1 & OS1.2 & OS1.3 & OS1.4 & OS2.1 & OS2.2 & OS2.3 & OS2.4 & OS3.1 & $\begin{array}{l}\text { OS3.2 } \\
\text { OS3.3 }\end{array}$ & $\begin{array}{c}\text { OS3.4 } \\
\text { Averaged } \\
\text { value }\end{array}$ \\
\hline A & 0.338 & 0.238 & 0.367 & 0.588 & 0.621 & 0.597 & 0.348 & 0.536 & 0.476 & 0.290 & 0.422 & 0.565 & 0.449 \\
B & 0.173 & 0.111 & 0.200 & 0.401 & 0.220 & 0.282 & 0.223 & 0.174 & 0.304 & 0.159 & 0.279 & 0.356 & 0.240 \\
C & 0.174 & 0.132 & 0.195 & 0.393 & 0.275 & 0.293 & 0.158 & 0.165 & 0.299 & 0.523 & 0.258 & 0.368 & 0.269 \\
D & 0.301 & 0.181 & 0.296 & 0.513 & 0.573 & 0.566 & 0.294 & 0.499 & 0.414 & 0.215 & 0.384 & 0.544 & 0.399 \\
E & 0.375 & 0.266 & 0.384 & 0.600 & 0.659 & 0.678 & 0.426 & 0.588 & 0.497 & 0.294 & 0.467 & 0.592 & 0.485 \\
F & 0.110 & 0.078 & 0.174 & 0.291 & 0.192 & 0.202 & 0.128 & 0.120 & 0.212 & 0.094 & 0.228 & 0.345 & 0.181 \\
Averaged value & 0.245 & 0.168 & 0.269 & 0.464 & 0.424 & 0.436 & 0.263 & 0.347 & 0.367 & 0.263 & 0.340 & 0.461 \\
\hline
\end{tabular}

reductions (from g1 to g8) observed in Figs. 4 and 5 (top panels) for OS1.2, of over $70 \%$ for the emerged configurations (A: $74 \%, \mathrm{D}: 68 \%, \mathrm{E}: 77 \%$ ) and of about $60 \%$ for the submerged ones (B: $61 \%, \mathrm{C}: 63 \%, \mathrm{~F}: 58 \%$ ), are due not only to the defence structures but also to shoaling, frictional effects (at boundaries, like seabed roughness and porosity) and internal dissipation (e.g. viscosity, turbulence). For instance, configuration $\mathrm{G}$, with no breakwaters, also induces a significant global wave height dissipation of about $50 \%$, this being only accountable to shoaling, seabed friction and viscous dissipation. Such behaviours can also be observed for the other wave phases.

Hence, since the wave height is a characteristic that can be easily measured during an experimental laboratory campaign and gives an important feedback on the wave damping, differently from other hydro-morphodynamic features (e.g., wave kinematics, seabed friction), the net dissipation contribution of the different breakwaters for each configuration can be estimated as the difference between the dissipation of each "defended configuration" (A-F) and that of the "structurefree configuration" (G). Such a difference, which can be thought of as a "net wave damping" for the different defence structures, is defined as:

$\alpha_{\text {net }}=\alpha_{\text {structure }}-\alpha_{\text {free }}$,

where the damping promoted by the structure $(i=\mathrm{A}, \ldots, \mathrm{F})$ and free $(\mathrm{G})$ configurations are, respectively

$\alpha_{\text {structure }}=1-\left[\frac{H_{s}(g 8)}{H_{S}(g 1)}\right]_{i}, \quad \alpha_{\text {free }}=1-\left[\frac{H_{S}(g 8)}{H_{S}(g 1)}\right]_{G}$

The wave dissipation is evaluated between the most seaward (g1) and shoreward (g8) gauges. Each damping coefficient introduced in (4) may be seen as the difference between the wave height measured at $\mathrm{g} 1$ and g8, normalized with the wave height at g1, i.e. $\alpha=\left[H_{S}(\mathrm{~g} 1)-H_{S}(\mathrm{~g} 8)\right] / H_{S}(\mathrm{~g} 1)$. This has been done to account for the overall contribu- tion of the beach, either protected or not, like in (4), and consequently, to estimate the actual overall contribution of the protected beach versus the free one, like in (3). Hence, each contribution given by the breakwater, e.g., transmission, reflection, etc., has not been singled out in such an evaluation.

The relative behaviour for the different wave phases (OS1.1-OS1.4, OS2.1-OS2.4 and OS3.1-OS3.4) is the same for each given breakwater configuration (see Table 5). Simply referring to the mean values of the tested cases, the better efficacy of the emerged breakwaters (A, D and E) is confirmed because they provide values from about 0.4 to almost 0.5 , whilst the tested submerged structures (B, C and F) provide lower values, from about 0.18 to 0.27 .

Configuration E (largest emerged structure) is the most efficient; follows configuration A (emerged most onshore), then configurations D (emerged offshore), C (widest submerged), B (submerged most onshore) and, finally, F (submerged most offshore). Globally, for all the wave phases, emerged structures provide a "net" wave reduction that is almost twice that of submerged breakwaters.

Further, the longest and most superelevated waves (OS2) undergo the largest reduction by the structures, but similar to the shortest waves, whilst OS1 are less reduced. For the emerged structure configurations (A, D and E) the most "net" damped storm is OS2, whilst for the submerged breakwater configurations ( $\mathrm{B}, \mathrm{C}$ and $\mathrm{F}$ ) the largest reductions occur for storm OS3. For five of the structure configurations, the waves of OS1 decrease less than the other storms.

The analysis of the data reported in Table 5 is illustrated in Fig. 7. The net damping is analysed with reference to the Ursell number of the incident waves $\left(U r=H_{s, i} L_{p}^{2} / h_{i}^{3}\right.$, see the left panel) and also to the previously introduced dimensionless parameter $\chi$, only for the emerged structures (see the right panel). The use of the Ursell parameter is made because, whilst the functioning of emerged breakwaters is very much local (for which use of $\chi$ gives the best representation), that of submerged breakwaters involves also non-local dynamics that evolves over the entire beach and the breakwater geom- 


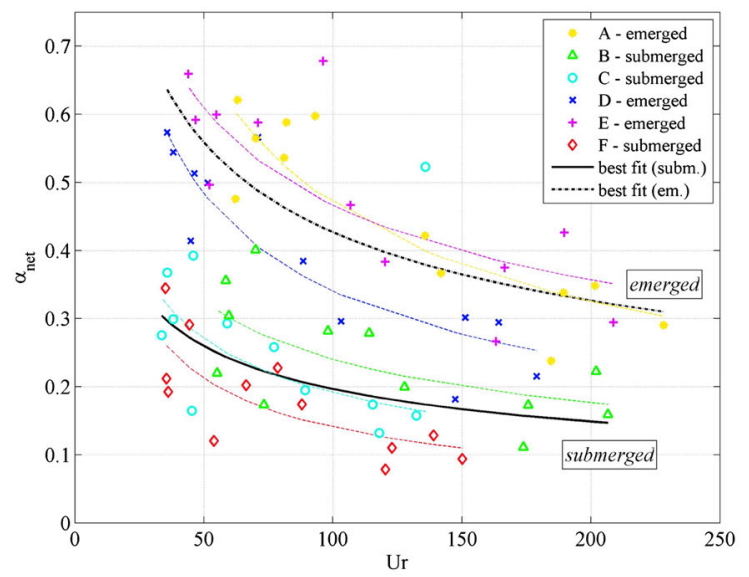

Fig. 7 Dependence of $\alpha_{\text {net }}$ on $\mathrm{U}_{r}$ (left panel) and on $\chi$ (right panel, only for emerged configurations) for all analysed wave conditions: data of submerged (B triangle, $\mathrm{C}$ open circle, $\mathrm{F}$ diamond) and emerged (A

etry is of lesser importance than the wave characteristics, which are suitably described by $U r$. Such a complex behaviour is also confirmed by the very small difference in the momentum flux provided by the different submerged breakwater configurations in the protected area (Sect. 3.5), and is further discussed in Sect. 4.

A power law has been used to fit the data for $U_{r}$, the emerged structures, which leads to $R^{2} \geq 0.62$ and a global coefficient $R^{2}=0.54$, whilst for the submerged cases it leads to better results if one data point (configuration $\mathrm{C}$, $\alpha_{\text {net }} 0.52$ ) is taken as outlier, with single $R^{2} \geq 0.40$, but a global $R^{2}=0.32$. This suggests that the net dissipation mainly depends on wave nonlinearity and frequency dispersion, with a decreasing trend for both emerged and submerged structures. Hence, the larger are the wave steepness and the frequency dispersion, i.e. the Ursell number, the larger is the wave damping throughout the beach. The lessefficient breakwater configurations are the smallest which are offshore located, i.e. D amongst the emerged and F amongst the submerged, similarly to what occurs for the transmission coefficient.

Moreover, use of the wave nonlinearity $H_{s, i} / h_{i}$ leads to much better results, i.e. $R^{2}=0.70-0.84$ for emerged structures (best fitting by a power law) and $R^{2}=0.52-0.72$ for submerged breakwaters (best fitting by a polynomial law). However, such a parameter is unable to give proper account of the role played by the wave shape (i.e. wavelength), goal that can be achieved by means of the Ursell parameter (left panel of Fig. 7). Further, use of the $\chi$ parameter does not lead to improved fitting: $R^{2}=0.24$ for emerged breakwaters (right panel of Fig. 7) and almost vanishing correlation for submerged ones (no fitting curve shown). However, it is clear that the more offshore structures are the less efficient in reducing the wave height.

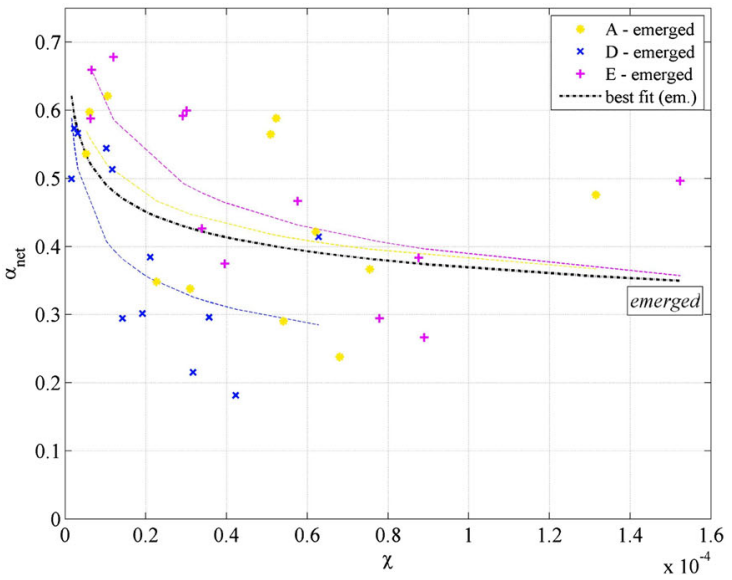

eight-pointed black star, D multi symbol, E plus symbol) structures are fitted both individually (dashed coloured lines) and globally (black lines) using power laws

\subsection{Net piling-up}

The analysis of the mean water-level distributions confirms that, when the waves overpass the breakwaters, in addition to undergoing a large energy reduction, they also induce a significant water-level increase (piling-up), especially at submerged breakwaters. As an example, the middle panels of Figs. 4 and 5 illustrate the abrupt water surface change in correspondence of the structures. A water-level reduction seaward of the breakwater is followed by a shoreward wave set-up, which is much more evident when the structures are submerged (Fig. 4), rather than emerged (Fig. 5). The data of the free beach configuration ( $\mathrm{G}$, in black), which also induces some mean water-level increase, represent the baseline for the interpretation of the data referring to the protected cases (A-F). Two "net" values of dimensionless piling-up are defined and made dimensionless using the wave height, due to the simplicity and accuracy to measure such a characteristic in the flume (see also Sect. 3.2):

$\Delta \eta_{\text {net, beach }}=\left[\frac{\Delta \eta_{\text {beach }}}{H_{S}(g 5)}\right]_{i}-\left[\frac{\Delta \eta_{\text {beach }}}{H_{S}(g 5)}\right]_{G}$,

$\Delta \eta_{\text {net, str }}=\left[\frac{\Delta \eta_{\text {str }}}{H_{S}(g 5)}\right]_{i}-\left[\frac{\Delta \eta_{\mathrm{str}}}{H_{S}(g 5)}\right]_{G}$,

where (5) is the net water set-up developed throughout the beach $\left(\Delta \eta_{\text {beach }}\right.$ is the absolute set-up), i.e. between $\mathrm{g} 2$ (at $x=$ $29 \mathrm{~m}$ ) and g8 (at $x=7 \mathrm{~m}$ ), whilst (6) is the set-up between the gauges just seaward and shoreward of each structure $\left(\Delta \eta_{\mathrm{str}}\right.$ is the absolute set-up), i.e. the same used to estimate the wave transmission (e.g., g6 and g7 for configuration E). Subscripts refer to the protected $(i=A, \ldots, F)$ and free beach $(\mathrm{G})$ configurations. 
The former approach is used for the submerged structure configurations, since a significant mean water-level variation occurs throughout the beach (e.g., see Fig. 4), whilst the latter, more local, approach is used for the emerged structure configurations, which mainly affect the hydrodynamics around the structure itself (e.g., see Fig. 5).

The difference between the behaviours of emerged and submerged structures is summarized in Table 6. Referring to the averaged values, the net piling-up is $\Delta \eta_{\text {net, beach }}=6-$ $10 \%$ for the emerged (A: $5.9 \%$, D: $10.5 \%$, E: $10.8 \%$ ), and $\Delta \eta_{\text {net,str }}=4-9 \%$ for the submerged (B: $7.9 \%$, C: $8.9 \%$, F: $4.2 \%$ ) breakwaters. However, the overall better efficacy of emerged breakwaters in inducing lower piling-up is confirmed if (5) is also used for emerged structures, this giving $\Delta \eta_{\text {net, beach }}<5.5 \%$, with submerged structures $\mathrm{B}$ and $\mathrm{C}$ providing fairly larger values. However, configuration $\mathrm{F}$ seems to be an exception, because its averaged value is lower than expected and single values are often smaller than those provided by the emerged configuration $\mathrm{D}$ for the same wave phase.

An overall interpretation of the piling-up is given in Fig.

8 , where almost all data (negative values are taken as out- liers) are interpolated using power laws. Best-fit curves of single configurations (dashed coloured lines) and of all submerged (black solid line) and emerged (black dash-dotted line) configurations are illustrated. Submerged breakwaters are characterized by fairly good single regression coefficients $\left(R^{2} \sim 0.5\right.$ for $\mathrm{C}$ and $\left.\mathrm{F}\right)$, and a global increasing trend of $\Delta \eta_{\text {net, beach }}$ with $\chi$. The smaller and more offshore configuration $(\mathrm{F})$ is the most efficient, providing lower piling-ups. Emerged breakwaters are characterized by poorer best fits, only configuration A being characterized by a reasonably good fit $\left(R^{2}>0.6\right)$, whilst the global trend is a decrease of $\Delta \eta_{\text {net, str }}$ with $\chi$. However, the data scattering, especially for configuration $\mathrm{E}$ which gives a trend opposite to the general one, suggests that for the emerged breakwaters no good fitting can be found; hence, no good physical interpretation of the dynamics itself.

Submerged structures, which induce lower wave transmission, give a larger piling-up for large values of $\chi$ (or wave steepness), whilst smaller values of $\chi$ mean a reduced impact of the structure on the sandy beach, leading to a larger transmission and lower piling-up.

Table 6 "Net wave piling-up" for all breakwater configurations and all the wave phase attacks

\begin{tabular}{lcccccccccccccccc}
\hline Conf. & Eq. & OS1.1 & OS1.2 & OS1.3 & OS1.4 & OS2.1 & OS2.2 & OS2.3 & OS2.4 & OS3.1 & OS3.2 & OS3.3 & $\begin{array}{l}\text { OS3.4 } \\
\text { Averaged } \\
\text { value }\end{array}$ \\
\hline A & $(6)$ & 0.021 & 0.018 & 0.026 & 0.059 & 0.093 & 0.092 & 0.060 & 0.124 & 0.071 & 0.054 & 0.052 & 0.033 & 0.059 \\
B & $(5)$ & 0.061 & 0.121 & 0.119 & 0.096 & 0.024 & 0.025 & 0.012 & 0.071 & 0.082 & 0.108 & 0.122 & 0.106 & 0.079 \\
C & $(5)$ & 0.129 & 0.146 & 0.142 & 0.086 & 0.046 & 0.026 & 0.084 & 0.05 & 0.091 & 0.094 & 0.107 & 0.069 & 0.089 \\
D & $(6)$ & 0.018 & 0.098 & 0.086 & 0.077 & 0.133 & 0.110 & 0.146 & 0.124 & 0.098 & 0.100 & 0.107 & 0.161 & 0.105 \\
E & $(6)$ & 0.088 & 0.077 & 0.184 & 0.166 & -0.005 & 0.051 & 0.072 & 0.153 & 0.127 & 0.082 & 0.120 & 0.183 & 0.108 \\
F & $(5)$ & 0.062 & 0.074 & 0.064 & 0.046 & 0.035 & 0.05 & 0.062 & 0.004 & 0.05 & 0.066 & 0.046 & -0.048 & 0.042 \\
\hline
\end{tabular}

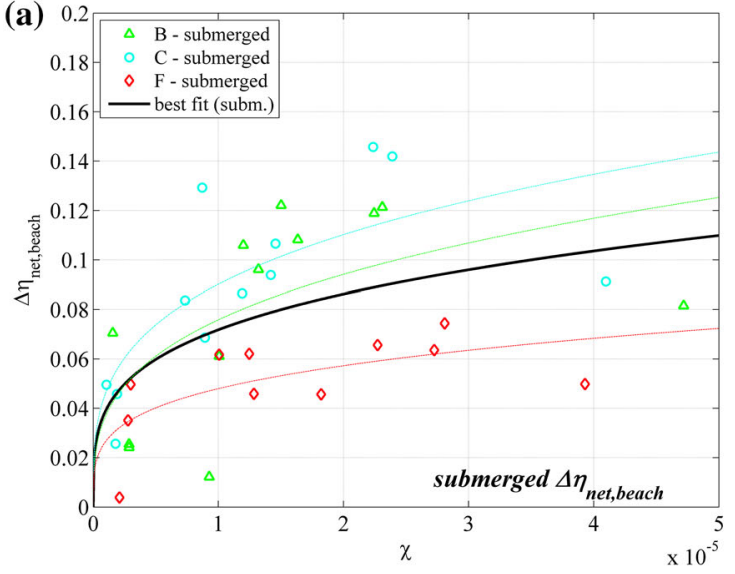

Fig. 8 Dependence of $\Delta \eta_{\text {net }}$ on $\chi$ for all analysed wave conditions and configurations: data of a submerged structures (B triangle, C open circle, $\mathrm{F}$ diamond), referring to piling-up developed throughout the beach, and $\mathbf{b}$ emerged structures (A eight-pointed black star, D multi symbol,

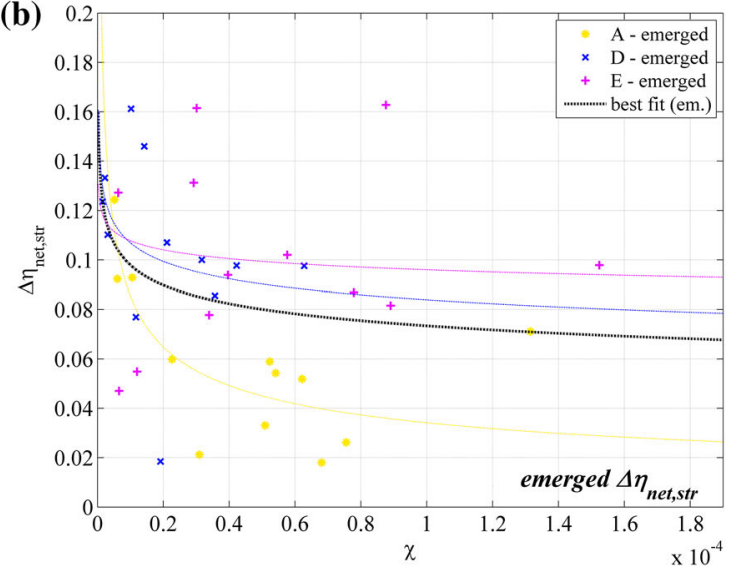

E plus symbol), referring to the piling-up structures are fitted both individually (dashed coloured lines) and globally (black lines) using power laws 
On the other hand, for emerged breakwaters larger values of $\chi$ give both lower transmission and lower or, at least similar water levels inshore and offshore of the structure. This is due to a very local effect, as it can be observed in Fig. 5 (and also occurring for other waves), where the water-level change of all emerged breakwaters is similar or smaller to that occurring in configuration $\mathrm{G}$ (black line) and sometimes it decreases moving shoreward (E). This makes the piling-up almost unaffected/independent of the structure geometry and wave characteristics.

\subsection{Experimental vs analytical wave transmission}

Comparisons of the experimental data with some theoretical laws for the transmission coefficient, obtained for low-crested coastal rubble-mound breakwaters, were also attempted. For this analysis, we used Van der Meer (1990), Van der Meer et al. (2005) and Buccino and Calabrese (2007), in the following indicated as VdM'90, VdM'05 and BC'07, respectively. All of them are suitable for both emerged and submerged structures. The comparison between experimental and theoretical data is shown in Fig. 9, as well as best-fit lines and bin averages of both submerged and emerged cases.

For emerged breakwaters (A, D, E), the values of $K_{t}$ estimated using VdM'90 and VdM'05 are very scattered and significantly underestimate the experimental data, whilst BC'07 provides a fairly better result. Conversely, for submerged breakwaters (B, C, F), data are better distributed around the bisector, especially BC'07's law (Fig. 9c). This, on average, slightly underestimates the experimental data, due to the poorer representation of data of configuration $\mathrm{F}$, whilst $\mathrm{B}$ and $\mathrm{C}$ data mainly fall around the bisector (see also the bin averages). The other two laws give poor comparisons, VdM'90 overestimating (Fig. 9c) and VdM'05 significantly underestimating the data.
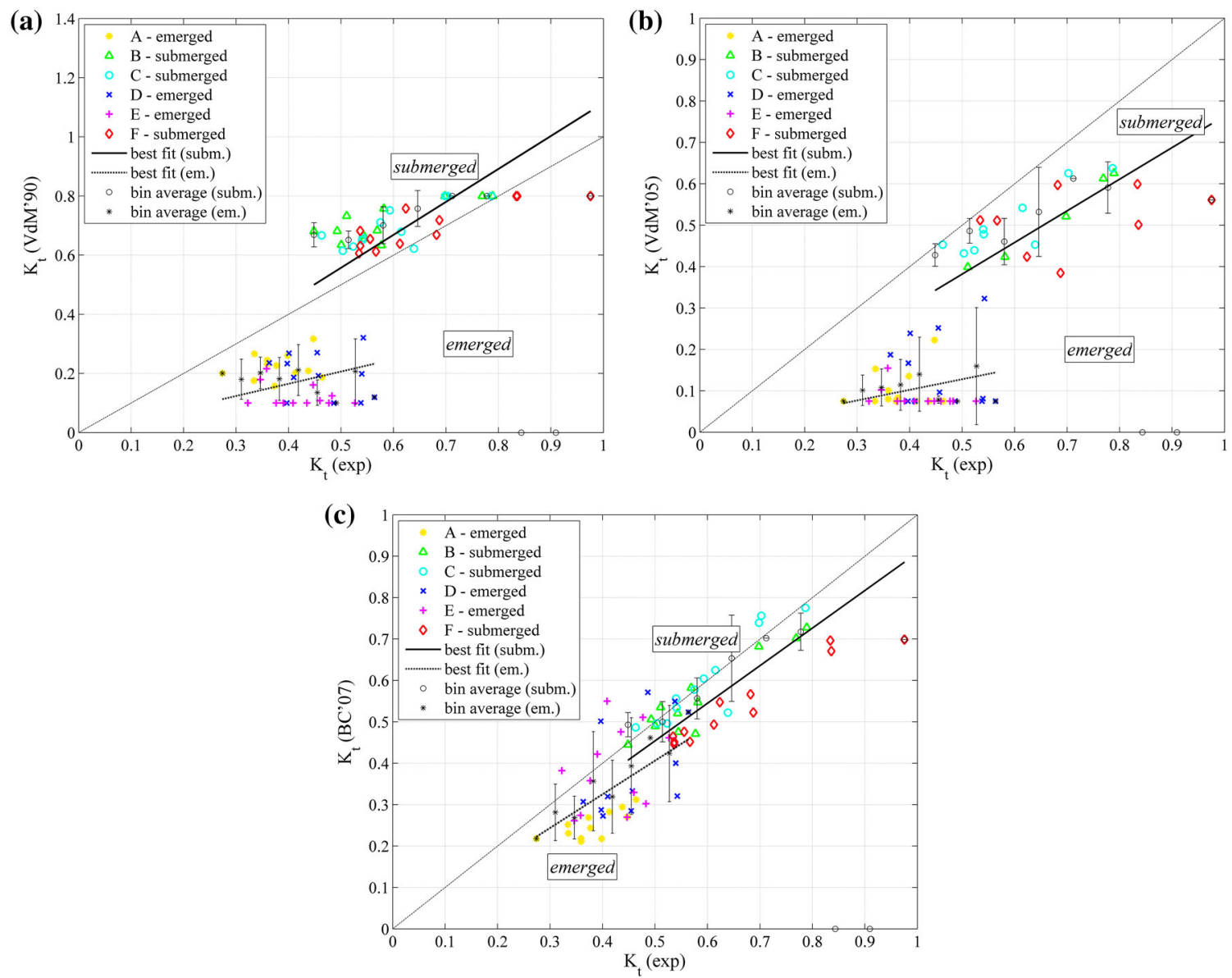

Fig. 9 Calculated (ordinate) against experimental (abscissa) values of $K_{t}$ for submerged (B triangle, C open circle, F diamond) and emerged (A eight-pointed black star, D multi symbol, E plus symbol) structure configurations: a VdM'90, b VdM'05, c BC'07. Best-fit lines and bin average of submerged and emerged configurations are also illustrated 

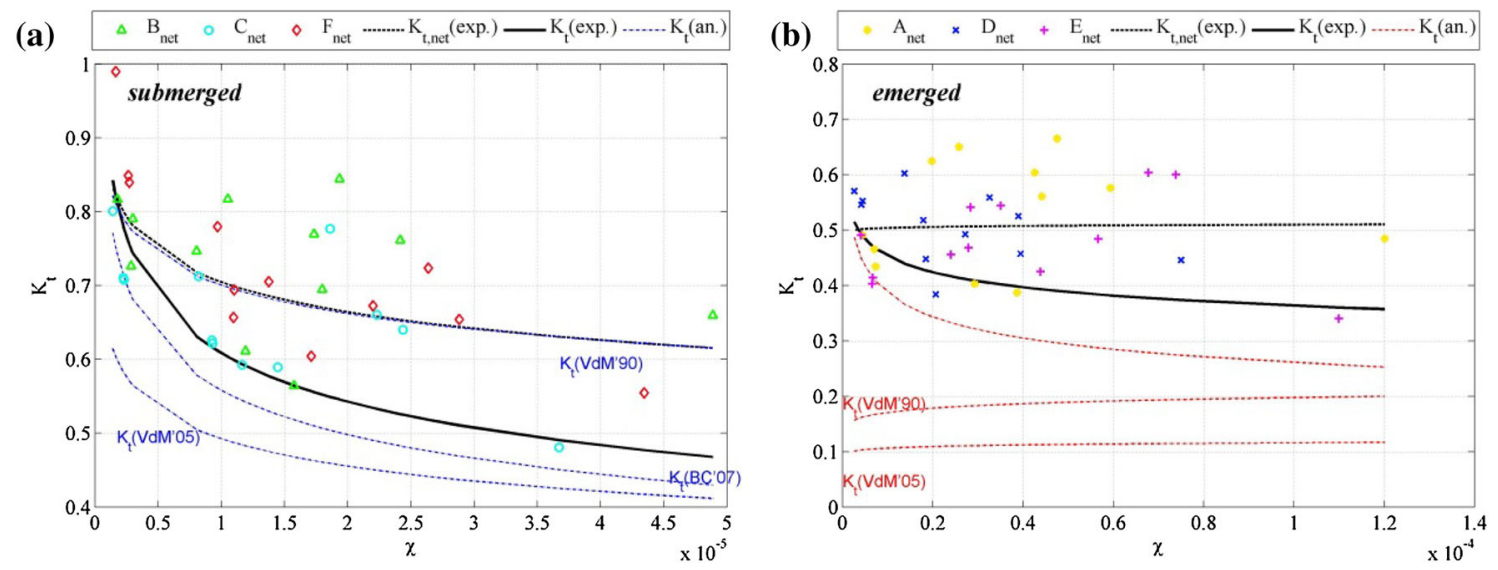

Fig. 10 Dependence of $K_{t}$ on $\chi$ of absolute (continuous lines) and "net" (dashed lines) experimental data and theoretical laws for a submerged and $\mathbf{b}$ emerged configurations. $K_{t, \text { net }}$ single data are also illustrated for each configuration

As already seen in the previous sections, the baseline configuration $(\mathrm{G})$ may also be used to get information about the net wave transmission. The expression of the "net wave transmission coefficient" can be easily obtained using wave height ratios, similarly to the net damping coefficient (3):

$K_{t, \text { net }}=1-K_{t, \text { free }}+K_{t, \text { structure }}^{*}=1-\left[\frac{H_{s, t}}{H_{s, i}}\right]_{G}+\left[\frac{H_{s, t}}{H_{s, i}}\right]_{j}$

Therefore, it is now possible to plot the experimental "net transmission coefficients" versus $\chi$ and search for power law fits. The resulting diagrams for emerged and submerged breakwater cases are shown in Fig. 10.

Mean values of the net transmission coefficient of about 70 and $50 \%$ are obtained for, respectively, submerged and emerged configurations. Comparing such values with the absolute ones (62 and $43 \%$, respectively), a net reduction of about $8-9 \%$, with respect to the absolute one, is obtained for both configuration types. Finally, both net and absolute wave transmissions provide mean values which are $20 \%$ larger when the structures are submerged.

Comparison of these "net wave transmission coefficient" curves obtained for the experimental data with the theoretical laws shows that for the emerged breakwaters no interesting agreement exists, whilst for submerged breakwaters a very close correspondence exists between the "net" data and VdM'90. The regression index of such theoretical law, when applied to experimental data, is $R^{2}=0.77$.

\subsection{Dynamics in the protected area and inundation of the emerged beach}

With reference to the above inshore breakwaters are more efficient than the offshore ones. In fact, the mean transmission coefficients of the offshore breakwaters (D-emerged and Fsubmerged) are larger than those of inshore similar ones (Aemerged and B-submerged).

Further, submerged breakwaters induce larger shoreline retreats than emerged breakwaters placed at the same position and for the same wave forcing.

With reference to the morphodynamic effects of the distance of breakwaters from the shoreline, inshore breakwaters seem to give slightly better environmental consequences than offshore breakwaters, in terms of short-term shoreline response and long-period beach evolution. More details on the morphodymamic results are described in Lorenzoni et al. (2012).

The numerical analysis of the morphodynamics proposed by Postacchini et al. (2016), referring to submerged breakwaters only, suggests similar behaviours and illustrates that the farther the structures are from the shore, the more intense are the observed bed variations.

Our analysis also confirms that the propagation of long waves over submerged breakwaters leads to the release of many shorter and smaller waves, as illustrated by Fig. 11a. Hence, the transformed inshore wave spectrum shows a large energy reduction and a peak translation towards higher frequencies (e.g. Battjes and Beji 1991). For the experiments at hand, an illustrative test result on configurations B (submerged close-to-shore structure) and G (unprotected beach) is shown in Fig. 11b. A large energy decay characterizes both configurations, from one of the most seaward gauges (g3, in blue) to that just seaward of the breakwater location ( $\mathrm{g} 7$, in red). A shift towards lower frequencies is evident, especially for the protected configuration, underlining a frequency dispersion occurring seaward of the structure. Further, the structure forces some energy dissipation across all the spectral band, with larger dissipations of longer/lowfrequency waves. Long waves $(\sim 0.06 \mathrm{~Hz})$ are characterized by a weak decay for the free beach configuration (dashed 
(a)

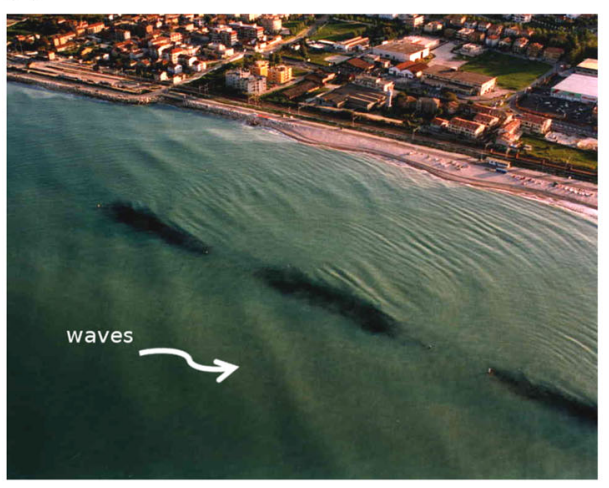

(b)

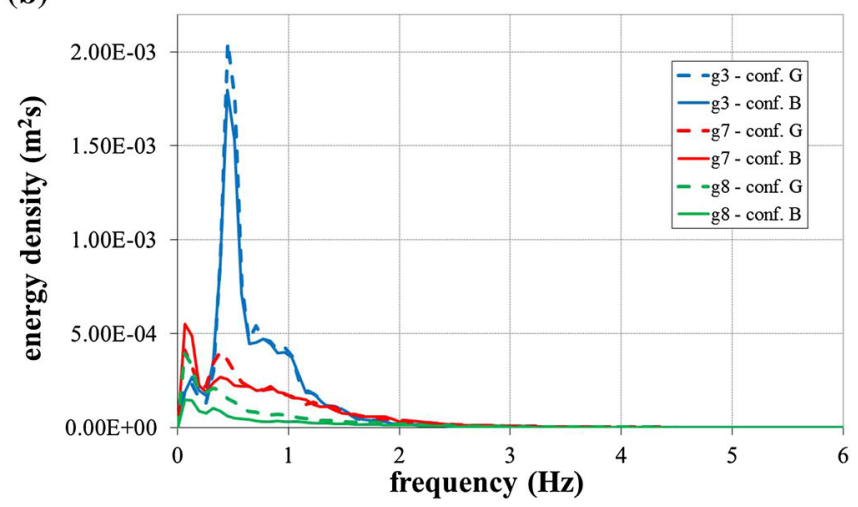

Fig. 11 a Propagation of long waves over submerged rubble-mound breakwaters and $\mathbf{b}$ tested spectra throughout the flume for configurations B (solid lines) and $\mathrm{G}$ (dashed lines)

green/red lines), compared with the large decay (about 4 times) achieved by use of breakwater B (solid green/red lines). This does not show a large dispersion towards larger frequencies, probably due to the relatively short waves tested, but reveals a significant dissipation of the longer wave components.

The wave propagation over and shoreward of the tested structures provides some fundamental feedback for the morphological changes of the nearshore area. Such changes can be used as proxy to investigate the swash-zone hydrodynamics. In particular, the cross-shore beach profile gradually modified during each wave attack: progressive shoreline retreats, steepening of the front scarp at the shore, progressive local erosion at the toes of the defence structure (mainly offshore) and formation/growth of emerged berms in the swash zone have been observed.

An illustration of the beach morphological evolution is given by Fig. 12 where a comparison of the berms obtained at the end of storm OS1 shows that submerged breakwaters lead to the generation of berms similar to those obtained at the free beach (Fig. 12, top panel), whilst emerged breakwaters give lower and narrower berms (Fig. 12, bottom panel). The independence of the swash-zone morphodynamics and erosion/deposition patterns from the distance-to-shore of the submerged structures has also been observed by Postacchini et al. (2016). Similar morphologies are forced by all the other storms, with the largest emerged structure (E) giving the smallest berm, whilst submerged breakwaters lead to berms comparable to those generated at the free beach $(\mathrm{G})$, configuration B giving a slightly smaller berm. This suggests that the structure-free beach $(\mathrm{G})$ and the submerged breakwaters $(\mathrm{B}, \mathrm{C}$ and $\mathrm{F})$ induce similar run-up elevations, whilst the emerged breakwaters allow for smaller (structures with of similar dimensions A, D) or significantly smaller (E) inundations.
Insights in the wave run-up can also be gained by estimating the momentum flux at the most inshore gauge (Archetti and Brocchini 2002; Hughes 2004). Based on the empirical law by Hughes (2004), the maximum momentum flux can be estimated as:

$\left[\frac{M_{f}}{\rho g h^{2}}\right]_{\max }=A_{0}\left(\frac{h}{g T^{2}}\right)^{-A_{1}}$,

where $A_{0}=0.64\left(\frac{H}{h}\right)^{2.03}$ and $A_{1}=0.18\left(\frac{H}{h}\right)^{-0.39}$. Such a law can be used for irregular/spectral waves, and spectral wave characteristics are used to estimate the various terms, i.e. $H=H_{s, \mathrm{~g} 8}$ is the significant height and $T=T_{m, \mathrm{~g} 8}$ the mean period, whilst $h=h_{\mathrm{g} 8}$ is the water depth, all estimated at gauge g8. Many of the analysed waves give very large peak periods at $\mathrm{g} 8\left(T_{p, \mathrm{~g} 8} \sim 15 \mathrm{~s}\right)$, due to the redistribution towards lower frequencies observed in shallower waters, as illustrated in Fig. 11b at g7 and g8. Hence, the mean period has been taken as more representative of the whole spectrum.

Figure 13 illustrates the evolution of the maximum momentum flux as function of the Ursell number $\left(\left.U r\right|_{\mathrm{g} 8}=\right.$ $H_{s, \mathrm{~g} 8} L_{p, \mathrm{~g} 8}^{2} / h_{\mathrm{g} 8}^{3}$ ), estimated at $\mathrm{g} 8$. The momentum is larger for the free beach configuration $(\mathrm{G})$, whilst the emerged structure configurations give the smallest values, with the largest breakwater (E) leading to the lowest values. This suggests that largest run-ups and inundations are associated with the free beach and submerged breakwater configurations, whilst emerged, especially offshore located, structures give reduced beach flooding (see also what observed in Fig. 12).

Further, though the spectrum peak shifts towards lower frequencies for all configurations in shallower waters (Fig. 11b) and similar inundation and morphological response within the swash zone (Fig. 12), emerged and submerged breakwaters induce similar frequency redistribution and nonlinearity reduction, the Ursell number being in the range 

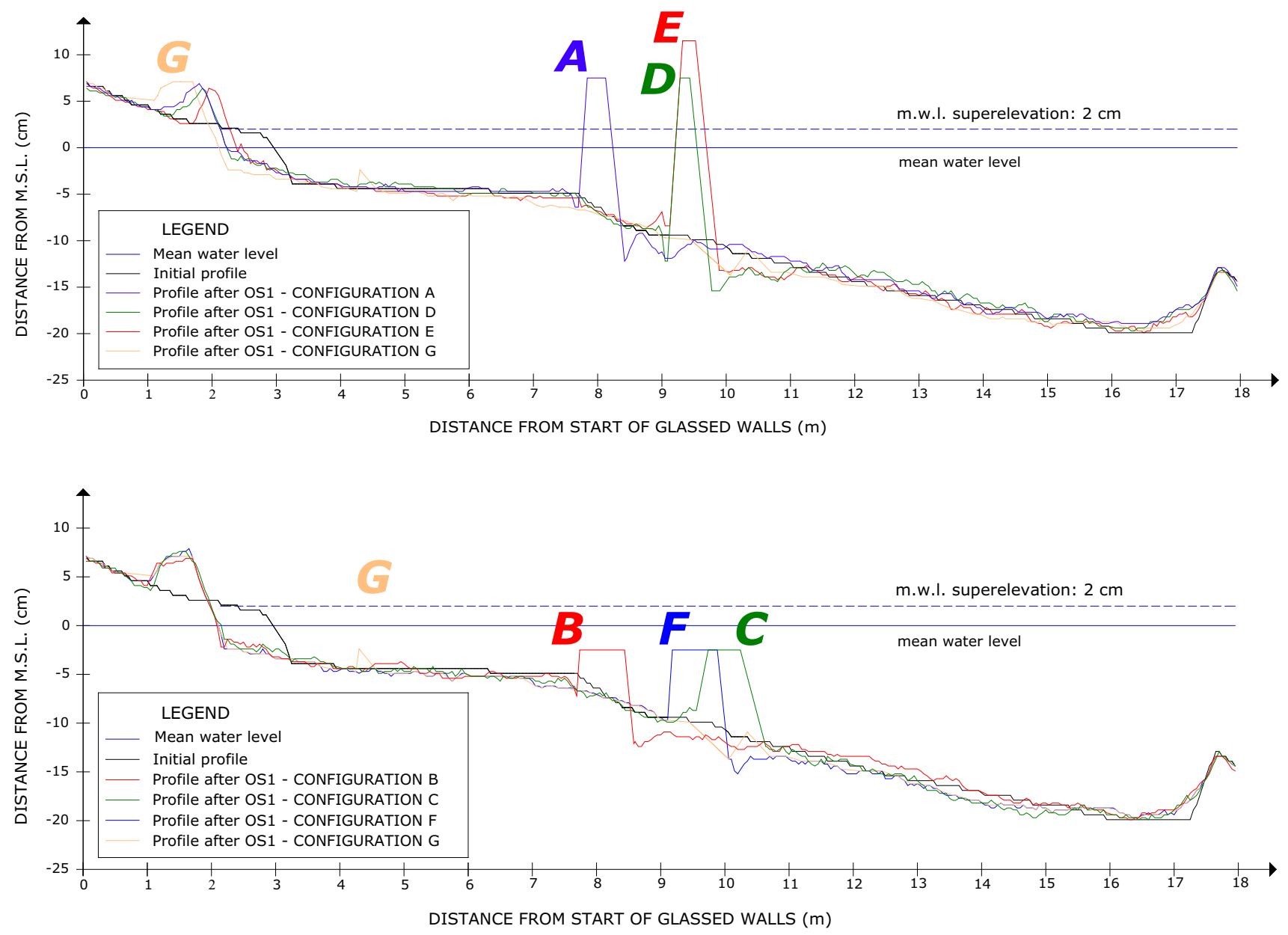

Fig. 12 Final bed profiles for the structure-free configuration $(\mathrm{G})$ and for the emerged (top panel) and the submerged (bottom panel) configurations

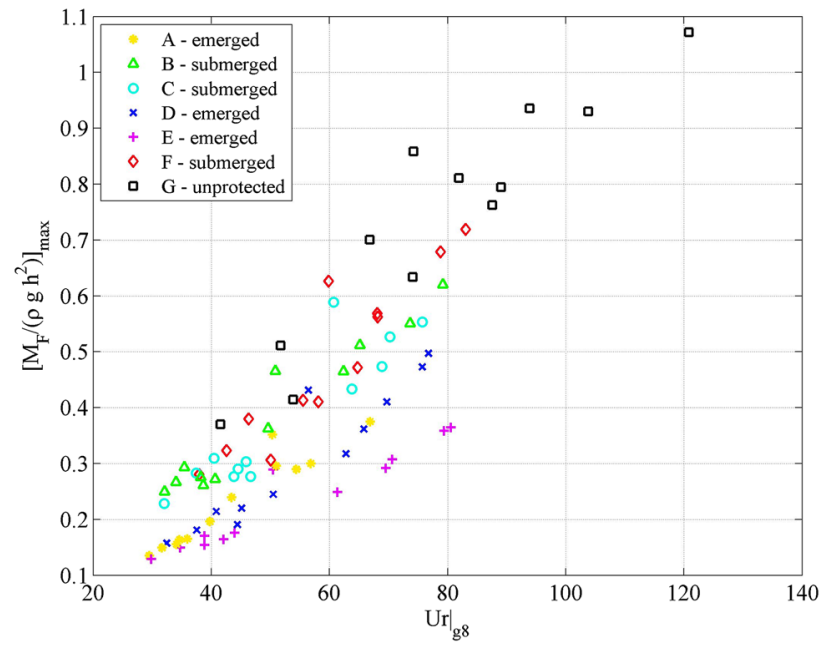

Fig. 13 Dimensionless maximum momentum flux versus Ursell number estimated at $\mathrm{g} 8$

$\left.U r\right|_{g 8}=(30-80)$ for all the protected configurations. Hence, as observed by Battjes and Beji (1991), breakwaters promote a wave frequency increase (i.e., wavelength decrease), but the structure geometry does affect the momentum flux and the consequent swash-zone inundation.

\section{Discussion and conclusions}

The hydrodynamic response of a protected beach to sea storms has been evaluated by means of the data collected through a number of laboratory experiments. Seven beach configurations, characterized by the same seabed topography, but different in the breakwater positioning and geometry (six were protected beaches, one free beach), have been tested inside a 50-m-long wave flume. Three different sea-storms, each characterized by four consecutive sea-states, have been run.

The wave transmission through the breakwaters has been estimated using resistive gauges. Existing theoretical laws to estimate the transmission coefficient have been applied to inspect their suitability. A "net wave transmission", evaluated by taking, as reference dissipation level, the wave damping provided by the free beach configuration has also 
been analysed and compared with theoretical laws. The wave damping over the submerged beach and the piling-up occurring in the protected area have also been calculated. Further, an analysis of the hydrodynamics and morphological response in the protected beach has been provided, to characterize the swash-zone dynamics and the inundation risk.

Fundamental findings are:

- A better estimate of the transmission coefficient can be achieved using the incident wave height estimated in the presence of the structure $\left(K_{t}^{*}\right)$, instead of using a free beach $\left(K_{t}\right)$, this properly accounting for the morphological feedbacks on the waves approaching the breakwater.

- Wave transmission coefficients $K_{t}$ and $K_{t}^{*}$ are larger for submerged (in the range 0.5-0.7) than for emerged (about 0.4 ) breakwaters, and in both cases, decrease with the wave-structure parameter $\chi$, which accounts for both wave steepness and breakwater dissipation potential, i.e. the ratio between structure width and freeboard.

- Values of $K_{t}$ measured on both submerged and emerged breakwaters are well represented by Buccino and Calabrese (2007)'s law.

- Some net characteristics have also been analysed, all accounting for the wave height measurements, which are the most reliable data collected in the flume, due to the difficulty/impossibility to undertake measurements, e.g. referring to wave kinematics, seabed friction.

- The net transmission over the structure $K_{t, \text { net }}$ is characterized by a poor fitting. However, for submerged breakwaters, it mainly decreases with $\chi$ and follows Van der Meer (1990)'s law.

- The net wave damping $\alpha_{\text {net }}$ over the submerged beach decreases with the Ursell number $U r$, whilst a weak dependence on $\chi$ has been observed for emerged breakwaters and no suitable fitting for the submerged ones. This means that nonlinearity and frequency dispersion are more important than the structure geometry, i.e. the more the waves are linear, the more they are damped by the structure.

- The net piling-up in the protected region, $\Delta \eta_{\text {net }}$, increases with $\chi$ for submerged breakwaters, and decreases for emerged breakwaters.

- The swash-zone dynamics significantly depends on the momentum flux of the transmitted waves, which increases with the local Ur. Submerged structures and the free beach induce similar fluxes, hence larger inundations, whilst emerged structures, especially that characterized by a larger freeboard, lead to smaller flux and run-up values.

In view of the above one could argue that submerged breakwaters are less efficient than emerged ones, because they lead to a larger wave transmission and piling-up in the protected area, hence inducing inundations comparable with those obtained over free beaches. Conversely, emerged structures significantly reduce both wave transmission and piling-up in the protected area, this forcing a smaller sediment transport within the swash zone and reduced inundations. They also provide a significant wave damping throughout the submerged beach.

The wave transmission induced at submerged breakwaters fits fairly well with a wave-structure parameter, whilst the damping over the submerged beach better fits with the Ursell number, which only accounts for wave nonlinearity and frequency dispersion. However, analysis of both transmission and damping leads to a similar conclusion, i.e. the more inshore-located or the larger are the structures, the more efficient they are. Although it is an intuitive finding, the present study reveals that the estimate of a net contribution is fundamental, due to the large impact of the unprotected part of the beach in the wave dissipation, and breakwater efficiency also depends on the interplay between structure geometry and its location within the submerged beach. Further, for a correct estimate of the breakwater efficiency, the piling-up generated within the protected area should also be accounted for, i.e. larger and closer-to-shore submerged structures, though more efficient in wave dissipation, lead to significantly larger piling-up rates, that could increase rip-current generation in a 3D framework. The larger is the structure efficiency, i.e. lower wave transmission, the larger is the piling-up. Further, both submerged structure geometry and location do not affect the hydro-morphodynamics in the protected area, leading to run-ups/inundations similar to those occurring within an unprotected beach.

Emerged breakwaters are characterized by a less-complicated behaviour. Similarly to submerged breakwaters, they are more efficient if they are large and close to shore, as for the submerged breakwaters, but do not induce negative feedbacks, like the large wave set-up occurring at submerged barriers. Further, the hydrodynamics in the protected beach totally changes, producing smaller swashzone inundations, significantly dependent on the breakwater dimensions.

On the other hand, whilst submerged breakwaters are less efficient in terms of inundation and sediment motion within the nearshore area, they do not generate significant localized scouring around the structures themselves. Conversely, emerged structures are much more efficient in the nearshore protection, but induce significant local scouring. It may be argued that the wave energy is

- either mainly dissipated at the structure and transmitted to shore, where the wave set-up allows for larger inundations and sediment motion (submerged breakwaters); 
- or mainly dissipated at the structure and transmitted to the bed, causing large local erosions (emerged breakwaters).

Finally, the actual wave dissipation occurs because of both wave breaking and friction (through the structure, at the seabed, etc.). The dominance of one of such mechanisms significantly influences both the observed mean water level and return flow.

With the aim to improve an overall analysis of breakwater efficacy, it seems essential to extend the present analysis to wider ranges of structure conditions (especially wider submerged breakwaters to reach the same transmission behaviours of the used emerged configurations) and wave features, to find the desired defence behaviours for the expected worst storm conditions. Once complete such a detailed analysis of a vertically $2 \mathrm{D}$ dynamics, it will be necessary to extend it to a fully 3D scenario in which breakwaters do not work as isolated structures but in arrays of structures.

\section{References}

Aminti P, Mori E, Fantini P (2010) Submerged barrier for coastal protection application built with tubes in geosynthetics of big diameter in Tuscany-Italy. In: Proceedings of the 9th ICG: International Conference on Geosynthetics, pp 1235-1240

Archetti R, Brocchini M (2002) An integral swash zone model with friction: an experimental and numerical investigation. Coast Eng 45:89-110

Battjes JA, Beji S (1991) Spectral evolution in waves traveling over a shoal. In: Proceedings of the Nonlinear Water Waves Workshop, Bristol, pp 11-19

Brocchini M, Bernetti R, Mancinelli A, Albertini G (2001) An efficient solver for nearshore flows based on the WAF method. Coast Eng 43:105-129

Brocchini M, Kennedy AB, Soldini L, Mancinelli A (2004) Topographically-controlled, breaking wave-induced macrovortices. Part 1 Widely separated breakwaters. J Fluid Mech 507:289_ 307

Buccino M, Del Vita I, Calabrese M (2013) Engineering modeling of wave transmission of reef balls. J Waterw Port Coast Ocean Eng 140(5):04014010

Buccino M, Calabrese M (2007) Conceptual approach for prediction of wave transmission at low-crested breakwaters. J Waterw Port Coast Ocean Eng 133(4):213-224

Burcharth HF, Hawkins SJ, Zanuttigh B, Lamberti A (2007) Environmental design guidelines for low crested coastal structures. Elsevier, Amsterdam, p 400

Calabrese M, Vicinanza D, Buccino M (2008) 2D wave setup behind submerged breakwaters. Ocean Eng 35:1015-1028

Gonzales M, Medina R, Losada MA (1999) Equilibrium beach profile model for perched beaches. Coast Eng 36:342-357

Hughes SA (1993) Physical models and laboratory techniques in coastal engineering. World Scientific, New York, p568

Hughes SA (2004) Estimation of wave run-up on smooth, impermeable slopes using the wave momentum flux parameter. Coast Eng 51(11):1085-1104

ISPRA (2012) Rete ondametrica nazionale, archivio storico dati. http:// www.idromare.it
Kikkert GA, Pokrajac D, O’Donoghue T, Steenhauer K (2013) Experimental study of bore-driven swash hydrodynamics on permeable rough slopes. Coast Eng 79:42-56

Kraus NC (1992) Engineering approaches to cross-shore sediment transport processes. In: Proceedings of the Short Course of the 23rd International Conference on Coastal Engineering. ASCE, pp 175-209

Kriebel DL, Dean RG (1993) Convolution method for timedependent beach-profile response. J Waterw Port Coast Ocean Eng 119(3):204-227

Larson H, Kraus NC (1989) Sbeach: numerical model for simulating storm induced beach change. CERC Report 89-9, US Corps of Engineers

Larson H, Hanson H, Kraus NC (1997) Analytical solutions of the oneline model of shoreline change near coastal structures. J Waterw Port Coast Ocean Eng 123(5):180-191

Lorenzoni C, Piattella A, Soldini L, Mancinelli A, Brocchini M (2005) An experimental investigation of the hydrodynamic circulation in the presence of submerged breakwaters. In: Proceedings of the 5th International Symposium on Ocean Measurements and Analysis, Paper 125

Lorenzoni C, Soldini L, Brocchini M, Mancinelli A, Postacchini M, Seta E, Corvaro S (2010) Working of defence coastal structures dissipating by macroroughness. J Waterw Port Coast Ocean Eng 136(3):79-90

Lorenzoni C, Postacchini M, Mancinelli A, Brocchini M (2012) The morphological response of beaches protected by different breakwater configurations. In: Proceedings of the 33 (15 Dec 2012), sediment.52. doi:10.9753/icce.v33.sediment.52

Losada IJ, Lara JL, Guanche R, Gonzalez-Ondina JM (2008) Numerical analysis of wave overtopping of rubble mound breakwaters. Coast Eng 55(1):47-62

Nobuoka H, Iric I, Kato H, Mimura N (1996) Regulation of nearshore circulation by submerged breakwater for shore protection. In: Proceedings of the 25th international conference on coastal engineering. ASCE, pp 2391-2403

Pilarczyk K (2000) Geosynthetics and geosystems in hydraulic and coastal engineering. CRC Press, Boca Raton, p 918

Pilarczyk KW (2003) Design of low-crested (submerged) structures: an overview. In: Proceedings of the 6th international conference on coastal and port engineering in developing countries, pp 1-16

Postacchini M, Brocchini M, Corvaro S, Lorenzoni C, Mancinelli A (2011) Comparative analysis of sea wave dissipation induced by three flow mechanisms. J Hydraul Res 49(5):554-561

Postacchini M, Russo A, Carniel S, Brocchini M (2016) Assessing the hydro-morphodynamic response of a beach protected by detached, impermeable, submerged breakwaters: a numerical approach. J Coast Res 32(3). doi:10.2112/JCOASTRES-D-15-00057.1

Ruol P, Faedo A, Paris A (2003) Prove sperimentali sul comportamento di una scogliera a cresta bassa e sul fenomeno del piling-up a tergo di essa. Studi Costieri 7:41-59 (in Italian)

Soldini L, Lorenzoni C, Brocchini M, Mancinelli A, Cappietti L (2009) Modeling of the wave setup inshore of an array of submerged breakwaters. J Waterw Port Coast Ocean Eng 135(3):38-51

Steenhauer K, Pokrajac D, O'Donoghue T (2012) Numerical model of swash motion and air entrapment within coarse-grained beaches. Coast Eng 64:113-126

Van der Meer JW (1990) Data on wave transmission due to overtopping. Delft Hydraulics Rep H986

Van der Meer JW, Briganti R, Zanuttigh B, Wang B (2005) Wave transmission and reflection at low-crested structures: design formulae, oblique wave attack and spectral change. Coast Eng 52:915-929 